\title{
A DINÂMICA DO FEDERALISMO BRASILEIRO NO TEMA DAS POLÍTICAS PÚBLICAS, CONTROLE SOCIAL E A COVID-19
}

\author{
THE DYNAMICS OF BRAZILIAN FEDERALISM IN THE THEME OF PUBLIC
}

POLICIES, SOCIAL CONTROL AND COVID-19

\section{Caroline Müller}

Doutorado e Mestrado em Direito pela Universidade de Santa Cruz do Sul, UNISC. Professora da Universidade de Santa Cruz do Sul, vinculada ao PPGD em DireitoMestrado e Doutorado-UNISC. Chefe do Departamento de Direito da Universidade de Santa Cruz do Sul. Membro da Rede Docente Eurolatinoamericana de Direito Administrativo. Membro da Rede de Direito Administrativo Social. Presidente do Comitê de Direitos Humanos da Universidade de Santa Cruz do Sul.

\section{Denise Bittencourt Friederich}

Doutorado e Mestrado em Direito pela Universidade de Santa Cruz do Sul - UNISC. Especialista em Direito Constitucional - ênfase em Direito Municipal pela Universidade Luterana do Brasil. Docente da Universidade de Santa Cruz do Sul - UNISC- e professora permanente do PPGD desta universidade.

\section{Resumo}

O objetivo desta pesquisa é discutir algumas particularidades decorrentes do sistema federalista brasileiro e sua dinâmica democrática, que acabam criando obstáculos tanto na tomada de decisão, quanto na implementação e controle social de políticas públicas, passando por um breve debate acerca dessa engenharia no caso COVID-19. Nesse sentido, o problema que se apresenta é: de que forma a engenharia do federalismo no âmbito de sua repartição de competências no Brasil impacta no tema das políticas públicas e na tomada de decisões em termos de políticas públicas sociais e controle social? Que respostas o federalismo brasileiro apresenta sobre a COVID-19? A hipótese é que o federalismo no caso brasileiro vai desde uma descentralização teórica a um modelo "cooperativo" predatório, mostrando-se extremamente relevante ao tema das políticas públicas sociais, inclusive para seu controle. Contudo, quando se trata de federalismo, há espaços para decisão, e decidir de forma cooperativa e articulada na engenharia do federalismo brasileiro é necessário e emergente, como indica o caso da COVID-19. O método do estudo é o dialético, e a pesquisa, bibliográfica. 
Palavras-chave: Controle social. COVID-19. Federalismo. Políticas públicas.

\begin{abstract}
The objective of this research is to discuss some peculiarities of the Brazilian federalist system and its democratic dynamics, which end up creating threats both in decision making, and in the implementation and social control of public policies, passing through a brief debate about this engineering in the COVID-19 case. In this sense, the problem presented is: how does federal engineering within the scope of its division of competences in Brazil impact on the theme of public policies and decision making in terms of social policies and social control? What answers does Brazilian federalism offer about the COVID-19? The hypothesis is that federalism in the Brazilian case ranges from theoretical decentralization to a predatory "cooperative" model, extremely relevant to the theme of social public policies, including for its control. However, when it comes to federalism, there are spaces for decision, and deciding in a cooperative and articulated way in engineering of Brazilian federalism is necessary and emerging, as indicated by the case of COVID-19. The study method is the dialectical and the bibliographic research.
\end{abstract}

Key-words: COVID19. Federalista. Public policies. social control.

\title{
1. CONSIDERAÇÕES INICIAIS
}

A engenharia do federalismo brasileiro possui total relevância para o tema das políticas públicas, o nível de centralização e descentralização da tomada de decisão, a coordenação das estratégias conjuntas para as competências administrativas comuns, os limites ao exercício das competências concorrentes da definição de normas gerais e suplementares. Além disso, impacta diretamente na ordenação e implementação de políticas públicas.

Partindo-se dessa premissa, este artigo busca discutir algumas particularidades decorrentes do sistema federalista brasileiro e sua dinâmica, que acabam criando obstáculos tanto na tomada de decisão, quanto na implementação e controle social de políticas públicas. Mais especificadamente, este estudo quer se dedicar ao tema das políticas públicas sociais.

O problema que está no centro dessa investigação é: de que forma a engenharia do federalismo no âmbito de sua repartição de competências no Brasil impacta no tema das políticas públicas e na tomada de decisões em termos de 
políticas públicas sociais e controle social? Que respostas o federalismo brasileiro apresenta sobre a COVID-19 no âmbito da repartição de competências? Visando a responder os problemas propostos e atingir o objetivo desta pesquisa, primeiramente buscar-se-á abordar o modelo federalista brasileiro, que vai de uma descentralização teórica ao modelo "cooperativo" predatório entre os entes federativos, para posteriormente enfrentar o papel das políticas públicas sociais no centro do debate da dinâmicas das políticas públicas, as possíveis conexões entre o tema políticas públicas e o controle social. Então, discutir-se-ão o federalismo e a atual questão da política pública de saúde no Brasil no enfrentamento da COVID-19 e qual a relação que deve prevalecer, no arranjo institucional das autonomias, os entes federativos. Ao final, buscando-se exemplificar a importância do debate, discorrer-se-á sobre o âmbito da repartição de competências administrativas e legislativas no caso COVID-19 e como se faz necessário decidir e decidir de forma cooperativa e articulada na engenharia do federalismo brasileiro.

\section{O MODELO FEDERALISTA BRASILEIRO: DA DESCENTRALIZAÇÃO TEÓRICA AO MODELO "COOPERATIVO" PREDATÓRIO ENTRE OS ENTES FEDERATIVOS}

A história constitucional brasileira revela que as Constituições não foram absolutamente originais em suas concepções acerca do sistema federalista. Em verdade, foram resgatar no direito estrangeiro as linhas gerais para construção e organização do sistema constitucional brasileiro de repartição das competências legislativa e administrativa, agregando-se, evidentemente, algumas características que distinguiriam o texto constitucional brasileiro dos demais Estados Federais, seja pela significativa extensão territorial, seja pelo número de entes federados que se optou em termos de autonomias com a Constituição de 1988, trazendo assim situações sui generis do federalismo brasileiro.

A influência de diferentes modelos de federalismo ao longo da sua formação histórica constitucional brasileira de certa forma ficou mais latente com a Constituição de 1988 na medida que impôs mais compromissos no âmbito das políticas públicas sociais, demostrando a complexidade que o arranjo das divisões de competências iria protagonizar.

Desde o surgimento do federalismo na história moderna, há mais ou menos 
três séculos, a adoção desse modelo depende dos contornos que assume em cada organização de Estado, bem como se diferencia também em conformidade com os níveis de comprometimento Estatal com os compromissos assumidos, especialmente com tema das políticas públicas e serviços públicos.

O federalismo é um modelo de Estado criado pelo movimento de independência norte-americana que visou a manter os núcleos de autonomia das 13 colônias inglesas, objetivo marcado em um documento histórico no ano 1776, com a Declaração do Bom Povo da Virgínia. Neste documento, as colônias se intitulavam "Estados Soberanos", cada um detentor de sua própria Constituição e com autonomia para elaborar sua própria Constituição, no qual preservariam suas liberdades, sua independência e soberania. A Declaração inovou na medida em que associou um governo central, dotado de soberania e independência em relação aos demais Estados-membros, a uma engenharia de manutenção da autonomia daquelas colônias que já estavam habituadas a gozarem de autodeterminação e não estavam dispostas a abandonar essa realidade. Assim, de uma confederação de estados com elevado nível de autonomia, nasceu o primeiro Estado federal do mundo. O desejo desse projeto foi se fazer forte perante a Inglaterra no processo de independência, sem, contudo, abrir mão do poder sob o qual as antigas colônias já haviam se estruturado de forma peculiar e com muitas singularidades umas em relação às outras. (MADSON; HAMILTON; JAY 1993).

De 1787, quando a Constituição dos Estados Unidos da América instituiu o federalismo ${ }^{1}$, até os dias de hoje, muito se alterou do modelo inicialmente idealizado. Os Estados soberanos foram fazendo adaptações e ajustando o federalismo a seus contextos históricos, geográficos e culturais, tornando hercúlea a tarefa de, em um

\footnotetext{
1 Interessa muito mais saber, em relação ao modelo da Constituição de 1787 , que ali foi instituído um sistema de repartição dualista rígido das competências legislativa e administrativa. Significa dizer que essa repartição se dá via atribuição de competências exclusivas e que, por isso, a matéria ou tema cuja competência é atribuída à União Federal automaticamente exclui no mesmo âmbito uma competência, seja ela legislativa seja ela administrativa, dos Estados-membros. Uma segunda característica do modelo norte-americano é o sistema de execução "direta". Esse sistema tem por pressuposto uma simetria ou identificação plena entre as competências legislativa e administrativa, isto é: o ente federativo ao qual foram atribuídas determinadas competências de cunho legislativo será também competente para a execução dessa legislação (competência executiva ou administrativa). O inverso também é verdadeiro: se ao ente federativo foram atribuídas competências de caráter administrativo acerca de uma dada matéria, será também dele a competência legislativa para regulamentar essa matéria. RODRIGUES, Itiberê C. V. Fundamentos dogmático-jurídicos do sistema de repartição das competências legislativa e administrativa na Constituição de 1988. In: REIS, Jorge Renato dos; LEAL, Rogério Gesta (Org.). Direitos sociais e políticas públicas: desafios contemporâneos. Santa Cruz do Sul: Edunisc, 2008.
} 
único conceito, definir o que é o federalismo. De lá para cá, o propósito inicial que levou os Estados a adotarem o federalismo oscila entre a união de Estados independentes em uma entidade distinta da Confederação, como ocorreu com no modelo norte-americano, ou, em um segundo propósito, a necessidade de evitar o desmonte de um estado unitário que, por atravessar alguma turbulência, viu-se na iminência da sua destruição completa pela cisão em unidade menores e a adesão ao modelo federativo serviu ao desiderato de manter, ainda que com algumas concessões, o poder central. A origem do federalismo brasileiro se enquadra neste último panorama.

Desse breve relato histórico que posteriormente influenciará o modelo brasileiro na Constituição de 1891, conhecida como nossa primeira Constituição Federalista e Republicana, é possível extrair ao menos linhas gerais do desafio criado pela adoção dessa forma de Estado, visto que, nessa arquitetura institucional, era preciso coordenar uma dupla autonomia territorial. Esta se caracterizava pelo fato de que, de um lado, o Estado nacional precisava se organizar de forma a conciliar os interesses políticos e maximizar os benefícios de uma comunidade unidade e centralizada, e, de outro lado, necessitava garantir a autonomia dos entes federados como um dos componentes fundamentais e identificadores do próprio modelo, o que acarretava a ideia de descentralização (LEVI, 1998).

Eis o desafio de compatibilizar as autonomias dos entes com a necessidade de se criar um núcleo central de governo, no qual havia a responsabilidade de promover políticas de integração e garantir o desenvolvimento de certa forma igualitário entre regiões tão distintas, buscando um maior equilíbrio entre elas.

Se originalmente, no modelo norte-americano, a Constituição foi elaborada em analogia às Constituições Estaduais e com respeito a preceitos já instituídos nelas, no caso brasileiro, nota-se outra destacada distinção, amparada na perspectiva de que as Constituições Estaduais, enquanto fruto do Poder Originário, encontraram todas limitações no âmbito da Constituição federal, além de uma série de normas de reprodução obrigatória e ainda o princípio da simetria sempre como base de interpretação em caso de omissões ou mesmo atuações legislativas que pudessem destoar da Constituição Federal. Ou seja, havia implicitamente uma ideia de alta limitação das autonomias regionais e locais.

Contudo, o modelo norte-americano não foi o único a influenciar a história do federalismo brasileiro. Pode-se dizer que, na Constituição de 1934, sem abandonar 
muitas das influências do sistema americano, passou-se a adotar o modelo federativo "cooperativo" alemão, marcado pelo redução das autonomias diante do aumento das competências do Poder da União, o que introduziu uma verticalização denominada de competências concorrentes, a fim de também dar maior centralização as competências legislativas da União Federal.

O modelo de federalismo alemão, cujas linhas básicas já estavam na Constituição de Weimar e foram mantidas na atual Lei Fundamental, opõe-se fortemente ao modelo de federalismo norte-americano, uma vez que aquele tem por base um sistema de federalismo "cooperativo". Este sistema de federalismo cooperativo permite, por um lado, a delegação de competências entre União e Estados-membros bem como, por outro lado, um sistema de execução legislativa indireto, é dizer: Estados-membros podem, em determinados casos, executar a legislação federal. (RODRIGUES, 2008, p323.)

É evidente que, no caso brasileiro, as diferenças surgem de causas como a ideológica, pois a República brasileira é também uma reação contra o modelo de monarquia parlamentarista europeia e, portanto, em um primeiro momento, voltou-se para a América, recepcionando então as formas político-constitucionais do modelo norte-americano. Outra causa é referente a sua extensão geográfica, como consequência da regionalização da política no período histórico pós-proclamação; e há ainda a motivação política, pela qual se pressupunha autonomia dos Estados da República velha. (ARRECHT, 2012)

Seja qual for a forma, mais autônoma ou mais cooperativa, a adoção desse modelo permite identificar algumas características em comum, resguardados obviamente os diferentes níveis de integração de acordo com a realidade com que se desenvolvem em cada país²: I - povo, enquanto elemento material do Estado Federal; II - diferentes níveis de representação, buscando garantir a representação da vontade dos Estados e da população; III - garantia de um Poder Judicial capaz de dirimir possíveis conflitos advindos da adoção desse sistema, também como forma de

\footnotetext{
${ }^{2}$ Destaca-se que existem no mundo cerca de 200 países, sendo que destes apenas 25 países são designados como federalistas, em que se destacam em extensão territorial e em riqueza. Desse modo, o Forum of Federations (2017), uma instituição que surgiu no Canadá e é uma organização de governança internacional que opera por meio de uma rede global de colaboradores para produção e troca de conhecimentos e práticas referentes ao federalismo no mundo. Assim, a referida instituição identificou 24 países federalistas no mundo, atualmente, sendo: Estados Unidos da América (1787); México (1824); Venezuela (1830); Suíça (1848); Argentina (1853); Canadá (1867); Brasil (1889); Austrália (1901); Áustria (1920); Alemanha (1949); Índia (1950); Paquistão (1956); Nigéria (1960); Malásia (1963); Emirados Árabes Unidos (1971); Espanha (1978); Rússia (1991); Bélgica (1993); Bósnia-Herzegovina (1995); Etiópia (1995); África do Sul (1996); Iraque (2005); Sudão (2005); Nepal (2007). (FORUM OF FEDERATION, 2017). (SOARES; MACHADO, 2018, p. 23).
} 
garantia e aplicabilidade dessa Constituição (ATALIBA, 1980).

Segundo Soares e Machado (2010), tradicionalmente os requisitos de um Estado Federal são: (i) Constituição Federal que distribua as competências dos entes federados e organize a relação entre eles; (ii) Divisão territorial do Estado nacional em subunidades denominadas entes federados; (iii) Poderes Executivo, Legislativo e Judiciário no âmbito nacional e subnacionais; (iv) Divisão de competências fiscais e administrativas entre os entes federados; (v) Legislativo nacional bicameral, com uma casa, representando as unidades autônomas; e (vi) Corte Suprema de Justiça por manter a unicidade e deliberar sobre a divergência entre a unidades autônomas entre si e destas com o poder central.

\begin{abstract}
Pode-se afirmar no mínimo três pontos essenciais: o conceito de Federalismo não pode desconsiderar a Constituição como ponto de partida; não pode deixá-lo ser extraído meramente fruto da práxis política ocasional, pois, do contrário, sempre que a prática política se altere ter-se-á que mudar o conceito do Federalismo, o que implica perder sua função de estabilização do sistema político e jurídico. Mas ao mesmo tempo que o Federalismo não pode ser o espelho da prática política de momento, seu conceito só pode ser adensado com elementos que, é óbvio, remetem a razões políticas (maior democracia, controle recíproco, autonomia etc.). E tais elementos são construídos e reconstruídos a todo instante. (BITENCOURT; RECK, 2012, p.155)
\end{abstract}

Desse conceito, é possível identificar uma complexidade no arranjo e coordenação dos poderes e suas organizações no sistema federativo, podendo dizer que será possível identificar múltiplos centros de Poder, que, no âmbito Federal, Estadual e Municipal vão coordenar seus respectivos órgãos, todos com poder decisão, de modo que cada Poder em cada nível da federação terá suas respectivas competências a partir das autonomias ${ }^{3}$ dos entes federado. Estes, em suas competências, terão de orquestrar os limites, sendo que as competências da União abrangem todo o território nacional, as dos Estados-membros abrangem apenas o âmbito do respectivo território do Estado-membro, enquanto as dos municípios o interesse local. Contudo, há de se respeitar a impossibilidade de um ente federativo criar obrigações contra o outro, que não aquelas já estabelecidas na Constituição federal. Dessa forma, a intervenção federal e Estadual preconizada no art.34 e art. 35 da Constituição Federal, como suspensão temporária e pontual das autonomias, deverá constituir-se em uma raríssima excepcionalidade, além de buscar garantir uma

\footnotetext{
${ }^{3}$ Art. $1^{\circ}$, caput, c/c art. 18, caput, parte final, c/c art. 19, CF 1988 - A Constituição assegura a autonomia a partir de três níveis federativos (União, Estados, Municípios), e depois assegura a autonomia desses três entes federativos tanto externamente (i.e. contra o poder religioso - art. 19, I) quanto internamente entre os próprios entes (art. $1^{\circ} \mathrm{c} / \mathrm{c}$ art. 18, caput, parte final, c/c art. 19, II e III).
} 
participação igualitária de todos Estados-membros na formação da "vontade" legislativa federal/nacional Senado Federal (cf. art. 46, $\S 1^{\circ}$, CF 1988), e paralela à Câmara legislativa de representantes do povo (Câmara dos Deputados, cf. art. 45, caput, CF 1988).

Visando evidentemente a manter as linhas gerais e a opção pelo pacto federativo de 1988, o Constituinte Originário buscou resguardar a adoção do modelo ao estabelecer o federalismo como princípio fundamental e impedir a secessão do pacto, conforme art. 1º, CF 1988 - "A República Federativa do Brasil, formada pela união indissolúvel dos Estados e Municípios e do Distrito Federal, constitui-se em Estado Democrático de Direito e ...", ainda resguardado como cláusula pétrea conforme Art. 60, $\S 4^{\circ}$, I, CF 1988 - "Não será objeto de deliberação a proposta de emenda tendente a abolir (...) a forma federativa de Estado". Tal norma impede juridicamente a abolição do Estado federal por meio de emenda constitucional que transforme o Brasil em Estado unitário ou mesmo de Províncias sem autonomia.

O federalismo brasileiro sempre foi marcado pela complexidade de suas relações, as quais buscam equilibrar suas diferentes influências. É consenso que o federalismo tem como característica-chave a existência de pelo menos dois níveis de governo, ditos autônomos, sobre o mesmo território e pessoas. Ainda assim essa característica do sistema político não é algo simples de captar, porque, em sua prática, apresenta uma enorme variedade institucional à qual correspondem diferentes formatos de distribuição vertical de autoridade sob a descentralização territorial que lhe é peculiar. E essa variedade institucional não pode ser devidamente compreendida pelos institutos formalmente vinculados à organização constitucional do Estado de tipo federal, o que se pode denominar como federalismo formal. (SOARES; MACHADO, 2018).

A descentralização, um dos conceitos mais presentes quando se trata de federalismo, está longe de assumir uma feitura única, pois se encontram na doutrina diferentes formas de observá-la, e, entre elas, a descentralização territorial costuma assumir relevância nesse debate. As formas de descentralização. Ainda há que se considerar que os usos do termo descentralização não se restringem às distinções quanto à distribuição territorial de autoridade, e sua aplicação a contextos bastante diversos the valeu um caráter polissêmico, ou seja, ele passou a abranger significados muito diversos, levando vários autores a um esforço para estabelecer definições e classificações para suas diversas modalidades. Uma dessas classificações distingue 
três tipos de descentralização: I) Funcional/horizontal: caracterizada pelo maior número de transferência de competências ou funções para pessoas jurídicas ou estruturas governamentais ante a forte presença da perspectiva da autonomia, receptores, entidades como fundações, empresas públicas e outras. II) Do Estado para a sociedade civil: a ideia de fortalecimento da sociedade civil, assumindo o protagonismos mais comunitaristas ou privatistas para agentes de mercado, o que inclui terceirizações, delegações, acordos de parcerias, transferências e mesmo diminuição da regulação estatal; III) Territorial/vertical, apostando na "transferência de poderes, competências ou funções para entes governamentais pertencentes a níveis inferiores ou menos abrangentes de governo, como estados ou municípios", talvez a mais típica expressão do federalismo . (SOARES; MACHADO, 2018).

De forma mais ampla, pode-se compreender a descentralização na dimensão de: I) política ou autogoverno, perfectibilizada por meio de eleições que determinam a gestão em diferentes níveis federativos; II) legislativa, com uma distribuição e reserva de competências legislativas próprias para os diferentes entes, com competências legislativas de ordem exclusiva; III) fiscal, a partir da garantia de recursos financeiros prevendo uma sistema de arrecada próprio e também de repasses de recursos ou transferências; IV) administrativa, com reserva de competências de ordem administrativa exclusivas e comuns, na prestação de serviços e implementação de políticas públicas. (FALLETI, 2006)

\section{MAS ANTE A CARACTERIZAÇÃO DAS MÚLTIPLAS DIMENSÕES DE DESCENTRALIZAÇÃO, POR QUE FALAR EM MODELO COOPERATIVO PREDATÓRIO?}

O modelo de coalizão do Presidencialismo ${ }^{4}$ brasileiro também tem significativos reflexos nessa relação com os poderes autônomos, com o chamado

\footnotetext{
${ }^{4} \mathrm{~A}$ expressão presidencialismo de coalizão foi empregada pela primeira vez em 1988 pelo cientista político Sérgio Abranches, passando a ser habitualmente utilizada na literatura e no diálogo político brasileiro para representar a característica de organização do poder político institucional brasileiro. Em artigo, Abranches ${ }^{4}$ desenvolve reflexões a respeito da pluralidade e da heterogeneidade da sociedade brasileira, bem como acerca das complexas realidades - social e econômica - que o Brasil apresentava. Esses fatores obrigatoriamente refletiriam na constituição das forças políticas, que, por seu turno, apresentavam sua dose particular de complexidade relacionada às fragmentações regionais e a aspectos históricos, como o clientelismo, de custosa extinção, que reinava em algumas regiões do país. ABRANCHES, Sérgio Henrique Hudson de. Presidencialismo de coalizão: o dilema institucional brasileiro. DADOS - Revista de Ciências Sociais, Rio de Janeiro. v. 31. p. 5-34, 1988.
} 
federalismo político, pelos diferentes níveis de atuação política nos âmbitos Municipais, Estaduais e Federal.

O problema não decorre apenas da relação entre Poder Executivo e Poder Legislativo. A questão é que a heterogeneidade basilar do país, a assimetria do federalismo brasileiro, a disparidade das estruturas de crenças políticas e relativas à democracia e à alta diferenciação ideológica se encontram no berço dos riscos de paralisia decisória e da complexidade da governança no país. O presidencialismo de coalizão impõe à presidência uma atribuição crítica no equilíbrio, na administração e na estabilidade da coalizão de modo que o chefe do governo comanda, orienta e articula a maioria. Mas, nesse específico padrão institucional, é indispensável que o presidente cultive o apoio da população, além de um comportamento proativo na gestão política da maioria. (ABRANCHES, 2001).

O líder de governo deve solucionar os embates e rivalidades, característicos das coalizões multipartidárias, e tentar nele não se envolver. Nesse aspecto, toda coalizão contempla a distribuição dos cargos no governo entre os partidos que a integram, e defende, ainda, que, na maioria das melhores democracias do mundo, onde existem coalizões, há uma fração considerável de políticos que atua para potencializar votos ou postos governamentais. Essa lógica política não é ilegal, se não estiver rodeada de corrupção e práticas lesivas ao interesse público (SCHIER, 2014).

É evidente que a busca pelo apoio política interferirá na gestão também das políticas públicas, refletindo muitas vezes maiores incentivos e direcionamento de programas por parte do ente central. Parece claro nesse momento vivenciado pelo COVID-19 que as questões de divergências políticas infelizmente têm-se sobreposto muitas vezes sobre o interesse público, a exemplo das medidas adotadas para enfretamento da pandemia, no caso da União, Estados e Municípios.

Por outro lado, os objetivos da República Federativa com a Constituição de 1988 já anunciavam a intencionalidade da Constituinte e a necessidade de um modelo cooperativo para atingi-la, para ":I, construir uma sociedade livre, justa e solidária; II garantir o desenvolvimento nacional; III - erradicar a pobreza e a marginalização e reduzir as desigualdades sociais e regionais; IV - promover o bem de todos, sem preconceitos de origem, raça, sexo, cor, idade e quaisquer outras formas de discriminação". Para tais finalidades, mostra-se absolutamente necessário o estabelecimento de um arranjo institucional capaz de aplacar as inúmeras desigualdades sociais, regionais e mesmo territoriais existentes em uma país tão 
grande e com tanta pluralidade econômica, cultural, etc.

A fim de atingir tal objetivo, Arretche (2012) compreende que a aposta do Constituinte de 1988 foi justamente um intenso processo que denominou de descentralização fiscal, impondo à União o papel de equilibrar as desigualdades especialmente regionais e locais, por meio de aumento dos percentuais de tributos a serem repassados pela União, enfraquecendo em certa medida o governo federal, que passou a ter de negociar com as lideranças políticas regionais e locais.

O cenário de competitividade estava desenhado e os prefeitos fortalecidos pelo voto direto, procurando extrair do governo federal o máximo de recursos tributários desvinculados de qualquer responsabilidade de gasto em áreas sociais, em troca de ofertarem apoio político e se tornam pequenos nichos eleitorais espalhados por várias partes do Brasil. Além disso, havia um sistema partidário de coalisões que permitia que partidos políticos formassem diferentes coligações em âmbito federal, estadual e municipal, o que tornou a barganha política muito além dos próprios desenhos do partidarismo.

Nesse contexto, a luta que será cotidianamente travada entre os próprios entes federativos no interior do processo de descentralização desenhado com a repartição de competências legislativas e administrativas vai cooperar para a lógica predatória do modelo federativo brasileiro, embalando o fortalecimento de disputas internas entre Estados. Nesses embates, as regiões mais abastadas tendem a ser contra políticas que centralizem atenções às regiões menos desenvolvidas, acirrando inclusive guerras identitárias que embalam sonhos dos inconformados independentistas, e assim a velha rivalidade entre Estados vira um campo também de batalhas para a dificuldade de implementação de políticas públicas mais universalizantes.

Exemplos emblemáticos são o eterno conflito entre Estados da região Sul/Sudeste $x$ Norte/Nordeste, sendo que os municípios dessa regiões possuem ainda grandes diferenças tributárias em face também da vocação de cada região, de suas diferenças climáticas e mesmo territoriais. Mas essa disputa também fica dentro dos próprios Estados e Municípios, haja vista a desigualdade distribuição das atividades econômicas, da renda e da prestação e acessibilidade de serviços públicos entre regiões metropolitanas e locais mais distantes de grandes centros urbanos, que sofrem com a ausência de recursos, como é o caso de tantos nos municípios do interior dos Estados" (ABRUCIO; COSTA, 1999).

Em verdade, o processo de emancipação dos pequenos municípios 
possibilitado pelo Constituinte Originário, que, apenas no ano de 1996, com a emenda Constitucional, alterou $\mathrm{o}$ art. 18 parágrafo $4^{\circ}$, tornou possível a existência de Municípios sem qualquer capacidade de gestão fiscal e administrativa sem depender dos repasses do Fundo de participação dos municípios, uma difícil equação entre suas competências administrativas e sua capacidade arrecadatória e fiscal para cumprir seus compromissos, tornando alguns "consumidores" de serviços prestados por outros municípios maiores.

É notório que tal processo não poderia ser feito mediante apenas a descentralização fiscal, e, assim, seguiu-se de uma organização de competências concorrentes $^{5}$, o que permitiu em certa medida que qualquer ente federativo pudesse implementar políticas sociais, mas simetricamente nenhum estava obrigado, produzindo em certa medida superposição de ações, desigualdades territoriais na provisão de serviços, e mínimos denominadores comuns nas políticas nacionais. Esses efeitos, por sua vez, são derivados dos limites à coordenação nacional das políticas (ARRETCHE, 2005.)

No caso brasileiro, a preponderância de alguns fatores tem tornado a federação um modelo de cooperação predatório, por características que também estiveram presentes na forma de organização e constituição da sociedade brasileira, pode-se citar: 1 ) o patrimonialismo; 2) o clientelismo; 3) a busca do interesse individual em detrimento do coletivo; 4) acordos informais nas relações formais em nome de governabilidade, as regras do jogo democrático que acontecem distantes da arena do debate público. O que a realidade retrata cotidianamente é a predominância das condições assimétricas distribuídas de acordo com os interesses em questão em cada momento conjuntural, além da baixa institucionalidade dos mecanismos de controle para assegurar os direitos e posições assumidas pelos pactuadores, que historicamente descumprem os acordos sem que haja para esse fato nenhuma punição (SOARES; MACHADO, 2018).

Nesse ínterim, podem ser elencados alguns fatores como extremamente relevantes da relação federalismo e políticas públicas, os quais a forma e o grau de intensidade da descentralização marcam uma influência direta (BUCCI; COUTINHO, 2019).

A política pública presume uma série de ações orquestradas que precisam de coordenação e organização para o clico da política pública, que vai, desde o momento

5 Vide art. 24 da Constituição, melhor abordado no último tópico desse estudo.

Revista de Direitos Fundamentais \& Democracia, Curitiba, v. 25, n. 3, p. 49-77, set./dez. 2020 
que a demanda entra na agenda governamental, até sua implementação e avaliação de política pública. O conceito de política pública adotado é um conceito complexo, porque pressupõe estar frente a um discurso que segue as demandas sociais em diferentes níveis dos quais surgem tais demandas, sejam de âmbito local, regional ou nacional. Essas demandas necessitam do direito e das organizações governamentais para sua implementação, sofrendo influência da sociedade ou de parte dela em uma tentativa de modificação consciente da sociedade que tem sempre presente o elemento democrático tanto em sua formação quanto em seu controle, a fim de que esteja em constante avaliação dado o caráter de provisoriedade enquanto existir a necessidade social que origina a demanda (BITENCOURT, 2013)

É evidente que o debate sobre as políticas públicas se dá no campo em que ambas as linguagens (direito e política) terão confluência para a realização das políticas públicas. Por isso, é importante demonstrar uma medida jurídica relacionada a políticas públicas, haja vista que elas não repousam no campo eminentemente político. Por um lado, a compreensão das políticas públicas observadas sob o enfoque jurídico é necessária, pois é sobre a ordem jurídica que se assenta o quadro institucionalizado para a aplicação das políticas públicas enquanto modo de operação do próprio Estado, por meio de seus poderes instituídos, bem como é no campo jurídico e com a máxima abertura democrática que se pode delinear sua incidência nos limites e padrões preestabelecidos por uma comunidade, expressos na sua Carta Constitucional. Por outro lado, cabe ao campo da política delimitar os modelos, metas, traçar diretrizes, externar os objetivos e finalidades e cabe ao direito conferir se no exercício dessa política foram respeitados o campo da legalidade e o respeito aos fundamentos balizadores da forma democrática (BUCCI, 2013).

Para tanto, se "o Federalismo nada mais é do que uma forma de configurar uma organização política”, evidentemente que imposta ao tema das políticas públicas, é importante ressaltar que “(...) ao mesmo tempo que o Federalismo não pode ser o espelho da prática política de momento, seu conceito só pode ser adensado com elementos que, é óbvio, remetem a razões políticas (maior democracia, controle recíproco, autonomia etc.)". (BITENCOURT, RECK, 2012, p 154.)

Portanto, o tema do federalismo além de ter total relação com a necessária alocação e planejamento de recursos para as políticas, tem influência direta com a possibilidade de maior aproximação da sociedade com as demandas sociais, quanto maior for sua descentralização, influenciando no nível de incentivo, participação e 
controle social das decisões políticas em termos de políticas públicas, maior será a pluralidade de nichos de decisão, podendo assim constituir uma forma de incentivo e aprimoramento da própria democracia.

\section{A RELAÇÃO DA DEMOCRACIA, CONTROLE SOCIAL E FEDERALISMO: TEMAS QUE IMPORTAM ÀS POLÍTICAS PÚBLICAS}

O debate acerca de qual a forma de Estado (unitário ou federal) oferece as melhores condições para o controle social justifica-se especialmente em países de democracia ainda em fase de implementação, como é o caso brasileiro, de democracia recente e que, não raro, erguem-se reivindicações por parte da população pelo seu próprio fim sob o velho argumento de combater a corrupção e resgatar valores morais que parte da população acredita estar em risco. Assim, evidenciam-se a fragilidade dos instrumentos democráticos no Brasil e a necessidade de melhor compreender as formas como ela se concretiza a partir de uma categorização com vistas ao aprimoramento da compreensão, implementação e utilização dos seus potenciais emancipatórios. Por essas e outras razões, a relevância da investigação acerca da relação entre democracia e seus desdobramentos.

Não foi, com isso, o federalismo pensado como uma engenharia capaz de ampliar o controle social, longe disso. No DNA do federalismo, está muito mais uma forma de manutenção de poderes consolidados do que qualquer outra forma de ampliação e consolidação de um projeto democrático. Contudo, não é pelo fato de não ter sido a implementação do controle social a razão da criação do federalismo que ele deva manter-se excluído das observações que buscam conexões entre esta forma de estado e o regime de governo democrático.

Porém, o federalismo, enquanto gestão descentralizada do poder, é muito mais que um modelo teórico. É sim uma formatação dependente muito mais das práticas instituídas dentro de um Estado do que a sua nomenclatura atribuída nos textos constitucionais. Exemplo disso foi o Brasil durante a Ditadura Militar que previu, na carta política de 1967, a forma federativa, porém se vivenciaram o fim do autogoverno estadual conquistado pela Constituição de 1946 e a centralização fiscal e administrativa na União. (SOARES; MACHADO, 2018)

Levitsky e Ziblatt (2018) apresentaram fortes indícios da falência da democracia liberal ao indicarem ataques a diversos direitos fundamentais com 
subterfúgios irracionais e egocêntricos e apoiados pelos cidadãos que desconsideram direitos como a liberdade religiosa, o respeito étnico, a igualdade entre homens e mulheres, etc. A democracia liberal, consolidada após a Guerra Fria, assenta-se no equilíbrio ou cooriginariedade (HABERMAS, 2007) entre o princípio democrático e os direitos fundamentais. Ocorre que muitos direitos fundamentais (como liberdade religiosa, direitos sociais como saúde e educação) dependem de uma troca com as especificidades de cada local. Como exemplo, o direito fundamental à saúde requer um olhar atento para as questões climáticas de cada região do país porque, em um país com as dimensões do Brasil, há uma variação muito grande de temperatura, umidade do ar, etc, que propicia o surgimento de doenças distintas.

Então, as políticas públicas destinadas a esse direito fundamental precisam outorgar aos entes federados competência suficiente para dar conta de atender a necessidades específicas de cada região. Em outras agendas, como ocorre com o ordenamento e ocupação do solo urbano, os estados federados oferecem melhores condições para o empoderamento de atores sociais locais que, sem um modelo de distribuição de competência para as entidades políticas menores, jamais teriam chances reais de serem ouvidos. A partir dessa constatação, a Constituição brasileira de 1988 outorgou aos municípios a competência de elaborarem seus Planos Diretores com a participação social dos munícipes que posteriormente poderão realizar o controle da implementação da referida lei. Por isso, o argumento segundo o qual a descentralização territorial equivaleria ao aumento de minorias regionais, e, por conseguinte, representaria um atentado à democracia nacional é posto em xeque. Logo, Estados federados estão melhores preparados para este engenhoso equilíbrio. (SOARES; MACHADO, 2018)

Contudo, de forma alguma se quer dizer que estados unitários não possam ser democráticos. Existem estados unitários que são retratos de democracias plenas (EUI,2019).Como exemplo, cita-se o caso do Uruguai, um estado unitário e um dos mais democráticos da América Latina. Também a Espanha, a França, a Suécia, a Dinamarca são bons exemplos de estados unitários com excelentes níveis democráticos. Da mesma forma, temos estados federados bem colocados nesse ranking. Então, por si só a classificação em unitário ou federado não determina o nível democrático de um estado. Mas a descentralização territorial e a respectiva fatia de competência para a tomada de decisão catalisam o controle social.

Não por coincidência, sempre que dois movimentos autoritários suprimem 
toda forma de controle social, como o fascismo e o nazismo, promovem a centralização de poder nas mãos de um poder central. Não se conhece, na história da humanidade, nenhum regime autoritário que trouxe consigo descentralização territorial de poder (ALBRIGHT, 2018). No Brasil, não foi diferente: o regime militar implantado em 1964 revogou autonomia dos entes federados, concentrando nas mãos da União as competências mais importantes, inclusive a de indicar governadores e prefeitos.

A democracia sustenta-se sobre dois pilares: a participação social e o controle social. Ou seja, a ideia central é que ambos, participação social e controle social, são instrumentos que visam a concretizar o ideal democrático vigente nas constituições contemporâneas. Embora receba variações na doutrina, para a distinção entre controle social e participação, este trabalho tem como ponto de partida a "decisão". Controle é a possibilidade de uma decisão ser substituída por outra, e a participação social consiste na existência de canais institucionais de interação com a sociedade na gestão governamental, com a presença de novos sujeitos coletivos nos processos para a tomada de decisão das escolhas públicas (BITENCOURT, RECK, 2018). Nem sempre a tomada de decisão da administração pública ocorre com abertura à participação popular e, ainda nesses casos, o controle social em tese é possível. Visto sob este último ângulo, "os processos de controle são, assim, processos de legitimação tardia que implicam o resgate da normalidade constitucional" (PEREIRA, 2010, p. 208). Aqui, garante-se a força normativa da constituição, na medida em que o controle social fiscaliza a normalidade das escolhas políticas mesmo que estas tenham sido tomadas à revelia da participação social.

Em contextos democráticos, sejam democracia plenas ou democracias incompletas (EUI, 2019), a relação entre controle social e a forma de Estado tem ganhado destaque. Isso porque se deseja compreender se a descentralização territorial e a respectiva outorga de autonomia fiscal, política e administrativa permitem um controle social mais efetivo e, por conseguinte, a concretização do valor democrático dos Estado contemporâneos.

A ideia central que interessa a esta pesquisa refere-se à relação entre federalismo e democracia. Mais especificamente: a forma federada de estado impulsiona o controle social e, consequentemente, aprimora o modelo democrático? Ocorre que muitas divergências pairam sobre esta relação, se é que ela existe, pois 
vigência de um governo democrático estável em determinados contextos de pluralidades territoriais (Lijphart, 2008). Outros autores apontam que o federalismo, a depender de algumas variáveis que definem sua conformação, pode ser um constrangimento à democracia (demos constraining) (Stepan, 1999). (SOARES; MACHADO, 2018).

De um lado, estão os que acreditam que o federalismo acentua as possibilidades de grupos locais se imporem, prejudicando políticas públicas nacionais, especialmente as sociais, que demandam uma agenda nacional construída nacionalmente e não em nível local. Desta forma, um estado unitário, cujo debate com a sociedade fosse de escala nacional, traria melhores respostas para as tais políticas públicas. De outro lado, há aqueles que defendem a tese segundo a qual o controle social é potencializado em estados federados, principalmente quando as diferenças culturais, sociais e econômicas são abismais dentro de um mesmo Estado soberano. Neles, a centralização das decisões políticas pode catalisar o ambiente de divergência, chegando à insustentabilidade do próprio Estado. Em tais situações, a manutenção da unidade nacional pode depender da descentralização do poder central, sob pena de aniquilar reivindicações locais. (ARRECHET, 2002).

O sistema federativo que privilegia o exercício do controle social no âmbito das políticas públicas favorece a qualificação dos processos decisórios. Soares e Machado (2018) sistematizam os argumentos favoráveis e contra a relação entre federalismo e ampliação do controle social. Para os defensores do federalismo como modelo adequado para o aprimoramento controle realizado pelos cidadãos, a proximidade física entre governantes e governados encorajaria a participação política deste porque conseguiriam identificar o quanto essa decisão Ihes influenciaria, e, posteriormente, conseguiriam fiscalizar sua implementação, ganhando também em sede de accountability e responsividade dos governos. No mesmo sentido, a descentralização seria uma fermenta para suprir os déficits democráticos do sistema eleitoral representativo majoritário, já que possibilita a inclusão dos grupos excluídos dos canais de participação social no processo de tomada de decisão. Em sentido contrário à relação entre federalismo e controle social, destacam a falta de evidências de que a descentralização para unidades federativas menores não ocasionaria a dominação de grupos locais mais fortes suprimindo os mais fracos. Esse quadro decorreria principalmente das fragilidades da imprensa local, deixando os grupos mais débeis suscetíveis da intimidação e dominação. Nessa perspectiva, as decisões em escalas menores retirarriam da agenda nacional as questões gerais relevantes para a 
estruturação de grupos sociais e das relações de poder entre eles. Por último, outro argumento que nega ao federalismo seu potencial catalizador do controle social diz respeito à falta de evidência dos assuntos locais na atenção dos cidadãos em comparação com os assuntos nacionais. "A democracia federal [...] pode ser a melhor resposta porque garante expressão políticas a comunidades territoriais que recusam a condição de subordinação a um centro político nacional." Soares e Machado (2018, p. 34).

A experiência federativa brasileira apresenta problemas e desafios paras as políticas públicas, no geral, e para as políticas sociais, no específico. Entre esses desafios, há, por exemplo, aspectos pouco equitativos do federalismo político e seu sistema de coalizões, o papel dos Estados na dinâmica federal tripartite, a capacidade dos Municípios na implementação de políticas públicas e abertura a participação e controle social.

\section{O MODELO FEDERALISTA BRASILEIRO E A COVID-19: A PANDEMIA MOSTRANDO QUE ARRANJOS TEÓRICOS PRECISAM RESOLVER PROBLEMAS PRÁTICOS}

As polêmicas sempre são maiores envolvendo a questão das políticas públicas de políticas sociais ou redistributivas. Essas políticas, além de ter em seu núcleo o ideal de direitos sociais, buscam observar tais direitos como núcleo integrante da condição de cidadania em uma dimensão nacional, e com elas vêm problemas relevantes ao federalismo, tais como os mecanismos necessários para coordenação e cooperação intragovernamental. Explicando de outra forma, se o federalismo busca também preservar um espaço amplo para decisão decorrente da preservação da autonomia, por outro, há necessidade de preservação de espaços decisórios pelo governo central, para que se possa fazer a redistribuição, ou seja, tirar de uns em detrimento de outros sem que todos estejam necessariamente de acordo. É claro que tais arranjos criaram constantes espaços de conflito no federalismo.

Assim, objetivos nacionais fixados para políticas sociais nos casos concretos
poderão ter sua realização condicionada a que sejam assumidos também
como objetivos regionais ou locais por entes governamentais autônomos, o
que, não ocorrendo, poderia colocar em xeque sua realização. Em especial no
caso daquelas políticas que propõem a realização de garantias sociais plenas
a todos os cidadãos, variações decisórias locais podem gerar distintos padrões
de ofertas de benefícios ou serviços sociais. No caso daquelas políticas que 
propõem nacionalmente um mínimo social, ao menos em tese, seriam aceitáveis variações regionais, desde que acima desse mínimo. Mas não se deve descartar a hipótese de que, mesmo nesses casos, o mínimo social nacional poderá ser comprometido por fatores como externalidades negativas oriundas de decisões locais de certas jurisdições e incidentes sobre outras, de modo que, ainda assim, a diversidade decisória poderia comprometer até mesmo o mínimo social. (SOARES; MACHADO, 2018, P.65)

Creio que dois exemplos possam ser citados para elucidar tal afirmação, a política nacional de saúde e a política nacional de educação. Imagine-se um objetivo nacional da política pública de educação elevar a qualidade do ensino, mas que, mesmo que o plano local esteja de acordo, discorde sobre qual a forma mais adequada para elevar os padrões educacionais. Ou ainda, certo que a realização desse objetivo suporia a mobilização dos governos estaduais e municipais, mas haveria obrigatoriedade de fazê-lo, e de que modo? (ARRECHET, 2005).

É possível, portanto, que sob determinadas configurações institucionais, ocorram de fato restrições de interesses territoriais à formulação, ao desenvolvimento ou mesmo aos resultados territorialmente uniformes de políticas públicas de abrangência nacional em países federativos, razão pela qual é sempre relevante buscar a compreensão dessa organização a partir da dogmática constitucional da repartição de competência em cada Estado federal. (BERCOVICI, 2006)

O caso COVID-19 trouxe à tona com força e emergência esse debate, especialmente no que se refere à política pública de saúde. Emerge a necessidade de compatibilizar a repartição de competência do âmbito do federalismo brasileiro, compatibilizar os interesses nacionais, regionais e locais a partir dos limites de atuação e autonomia de cada ente federativo no âmbito da concretização de políticas públicas para o enfrentamento dessa pandemia. É evidente que, sob influência dos conceitos da modernidade, espera-se uma tomada de decisão racional, ou seja, este trabalho aposta da perspectiva da ciência, seja médica, biológica, estatística, sociológica, jurídica ou filosófica, para produzir qualquer resposta compatível com a ordem constitucional.

Se o federalismo se vale da organização, a primeira pergunta a se fazer é quais as normatividades que é possível identificar para responder a tão complexa questão sobre as competências federativas no âmbito da saúde no caso COVID-19 e como ficam os arranjos do federalismo. Eis que o momento é de levantar todas as possibilidades de ordem normativa. 
No sistema constitucional brasileiro, tem-se que não se pode deixar de enfrentar o princípio normativo e hermenêutico trazido no art $1^{\circ}$, III, a dignidade da pessoa humana, o art $6^{\circ}$, que assegura o direito fundamental social à saúde combinado com o art 196 e art. 200, II, o qual atribui ao Sistema único de Saúde a competência para vigilância sanitária e epidemiológica.

A pergunta que se impõe é quem tem competência legislativa e administrativa no âmbito dessas duas temáticas, saúde e epidemiologia, que de fato, poderá inclusive implicar em outras competências, tais como medidas restritivas a própria liberdade de locomoção (em caso de necessidade de quarentena, por exemplo). Recorre-se, então, à divisão de competências constitucionais, tanto do art. 21 como competência administrativa da União, art. XVIII - planejar e promover a defesa permanente contra as calamidades públicas, especialmente as secas e as inundações; a competência administrativa comum (união, Estados e Municípios) do art. 23, V - proporcionar os meios de acesso à cultura, à educação, à ciência, à tecnologia, à pesquisa e à inovação; já em termos legislativos, é o art. 24, a competência concorrente 6 (expressamente Estado/Distrito Federal legislam concorrentemente) XII - previdência social, proteção e defesa da saúde; e pela leitura sistemática do art. 30, II, os municípios também poderiam suplementar em se tratando de interesse local, evidentemente

Tanto em se tratando de medidas de saúde de âmbito geral quanto de medidas de saúde no âmbito do SUS, a competência legislativa da União está restrita ao âmbito das normas gerais do art. 24, XII, sendo assim, os Estados e Municípios ainda

\footnotetext{
${ }^{6}$ Assim, além de possuírem competências privativas e comuns, ainda concorrem os entes federativos. A competência concorrente é típico caso de repartição vertical de competência em nosso país, no qual também se remete a ideia de cooperação. Ela expressa-se na possibilidade de que sobre uma mesma matéria diferentes entes políticos atuem de maneira a legislar sobre determinada matéria, adotando-se, em nocaso, a predominância da União, que irá legislar normas gerais ( $C F$, art. $\left.24, \S 1^{\circ}\right)$ e aos Estados estabelece-se a possibilidade, em virtude do poder suplementar, de legislar sobre assuntos referentes aos seus interesses locais $\left(\mathrm{CF}\right.$, art. $\left.24, \S 2^{\circ}\right)$, onde suplementar tem alcance semântico de pormenorização, detalhamento. Nesse sentido, tem-se definido a competência concorrente (CF, art. 24) como um condomínio legislativo entre a União Federal, os EstadosMembros e o Distrito Federal, daí resultando clara repartição vertical de competências normativas entre as pessoas estatais, cabendo, à União, estabelecer normas gerais (CF, art. $\left.24, \S 1^{\circ}\right)$, e, aos Estados-Membros e ao Distrito Federal, exercer competência suplementar (CF, art. 24, §2 ${ }^{\circ}$ ). Ainda, deferiu ao Estado-Membro e ao Distrito Federal, em inexistindo lei federal sobre normas gerais, a possibilidade de exercer a competência legislativa plena, desde que para atender as suas peculiaridades $\left(\mathrm{CF}\right.$, art. $\left.24, \S^{\circ}\right)$. Mais um exemplo em que o interesse geral e peculiaridades locais serão postos à prova enquanto critério definidor da repartição de competências. BITENCOURT, Caroline Müller, RECK, Janriê Rodrigues. Paradoxos do federalismo: uma observação pragmáticosistêmica. A\&C - Revista de Direito Administrativo \& Constitucional, Belo Horizonte, ano 12, n. 49, p. 151-176, jul./set. 2012.
} 
possuem uma competência legislativa suplementar sobre a matéria "saúde e epidemias". Contudo, há um problema de ordem prática: nunca houve um critério seguro de distinção entre o que integra as normas gerais e as normas suplementares, ou seja, mais uma vez é necessário decidir e construir os limites de atuação dentro do arranjo federativo.

Em termos de norma supralegal, é necessário considerar o Regulamento Sanitário Internacional 10.212/2020, no qual a Organização Mundial de Saúde decreta o estado de Pandemia e, portanto, emergência internacional em saúde e define o conceito de isolamento social. A partir daí, é necessário recorrer-se a duas normas ordinárias federais, no caso a Lei 8.080/90, pois é nela que as regras de vigilância sanitária e epidemiológica são definidas para enfrentamento de situações como COVID-19, e Lei 13.979/20, alterada posteriormente por duas Medidas Provisórias 926/20 e 927/20, que decreta a emergência de saúde pública de importância nacional, seguida pelo Decreto Regulamentar $10.282 / 20$, que na sua regulamentação define o conceito de serviços essenciais, com posterior alteração pelo Decreto $n^{0} 10.292$, de 2020. Ressalta-se que se pode extrair como lógica básica da referida Lei aquilo que é anunciado pelo "Art. $1^{\circ}$ Esta Lei dispõe sobre as medidas que poderão ser adotadas para enfrentamento da emergência de saúde pública de importância internacional decorrente do coronavírus responsável pelo surto de $2019 . \S 1^{\circ}$ As medidas estabelecidas nesta Lei objetivam a proteção da coletividade", ou seja, tempos de epidemia mundial saúde pública prepondera sobre os direitos individuais.

Desses dois diplomas normativos, um alerta se faz necessário, a Lei do SUS se mostra como uma espécie de lei "geral", ao passo que a Lei 13.979 assume um comportamento de lei "especial", pois deve ser aplicada em quando perdurar a epidemia decorrente da COVID-19. Sendo assim, pelas normas de introdução do direito brasileiro e como manda a boa doutrina de teoria geral do direito, esta última tem preferência de aplicação em relação à Lei do SUS, que serviria para eventual aplicação em caso de lacuna da lei especial. Outro problema de ordem prática que a Lei no caso de epidemia apresentou é que, ao fixar como as entidades podem agir, estabeleceu uma espécie de dependência de Estados e Municípios, ou seja, condicionou em certa medida o modo de exercício da competência suplementar por Estados e Municípios, estabelecendo uma base de restrições e limitações as quais não são previstas pelo texto constitucional no art. 24 da Constituição. 
Nesse ponto, destaca-se não o problema da execução da competência administrativa do art. 21, mas sim o problema na competência legislativa suplementar dos Estados e Municípios. Isso porque a Constituição previu ações de forma ininterrupta e contínua para administrar sistemas permanentes de serviços de combate a endemias e não-temporários, como uma vigilância sanitária, entre outros. Como ficaria uma restrição em face de sistemas temporários e emergências, como o caso COVID-19? Parece que tal previsão constitucional não há. Ele não regra diretamente a existência de sistemas temporários ou emergenciais, como é o caso.

Desses dispositivos legais, alguns artigos merecem destaque, da Lei 8080/90, o conceito de saúde em seu art. $3^{\circ}$. Os níveis de saúde expressam a organização social e econômica do País, tendo a saúde como determinantes e condicionantes, entre outros, a alimentação, a moradia, o saneamento básico, o meio ambiente, 0 trabalho, a renda, a educação, a atividade física, o transporte, o lazer e o acesso aos bens e serviços essenciais; art. 16. A direção nacional do Sistema Único da Saúde (SUS) compete, III - definir e coordenar os sistemasc) de vigilância epidemiológica; cabendo segundo o art. 17. À direção estadual do Sistema Único de Saúde (SUS) compete: IV - coordenar e, em caráter complementar, executar ações e serviços: a) de vigilância epidemiológica; e art. 18 IV - executar serviços. Destaca-se que o art. 16 usa utiliza para tratar da competência da União os verbos "Ill - definir e coordenar", o art. 17, ao definir a competência dos Estados, "coordenar de forma suplementar" e, ao enfrentar a competência do município, "executar os serviços".

Considerando que se trata de uma Lei para definir as competências e organização dos entes federativos em relação ao Sistema único de Saúde; considerando que trouxe a especificidade relativa a questões epidemiológicas, e, nesse caso, a União cria uma Lei especial 13.979/2020, haja vista que não se trata de uma situação recorrente da regularidade do funcionamento do sistema de saúde; considerando que a lei previu expressamente diferentes níveis de atuação, selecionando os verbos para configurar diferentes formas de atuação e obrigação dos entes federativos; considerando que a Constituição de antemão não define a abrangência de normas gerais e normas suplementares, como equalizar no sistema todas as variáveis levantadas?

$\mathrm{Na}$ tentativa de produzir tais respostas, o Supremo Tribunal Federal vem tentando enfrentar, ante inúmeras provocações, como equalizar as competências e limites de atuação de cada ente, lembrando que a jurisprudência em matéria de saúde 
não fornece nem de longe critérios seguros para diferenciar contextos de normas gerais e de normas suplementares. Passa-se a destacar algumas decisões que têm sido protagonizadas no âmbito desse debate no atual cenário brasileiro. Lembra-se de que será uma breve exposição de contextualização do debate e não uma análise minuciosa e crítica dos critérios e argumentos adotados nas decisões que serão referendadas.

Destaques para as ações diretas de inconstitucionalidades, a ADI 6341 e ADI 6343, visando à impugnação das Medidas Provisórias MPs 926 e 927, que em parte alteram a Lei 13.979/2020, tendo como centro da discussão se as medidas provisórias afastariam a competência dos Estados e Municípios para o enfretamento de medidas contra o coronavírus.

No julgamento conjunto sob relatório do Ministro Marco Aurélio, não houve declaração de inconstitucionalidade em relação às medidas provisórias, contudo, a maioria dos Ministros, seguindo o voto do Ministro Edson Fachin, aderiram à tese em medida cautelar "sobre a necessidade de que o artigo $3^{\circ}$ da Lei 13.979/2020 também seja interpretado de acordo com a Constituição, a fim de deixar claro que a União pode legislar sobre o tema, mas que o exercício desta competência deve sempre resguardar a autonomia dos demais entes". Basicamente dois argumentos destacam-se no voto do relator Marco Aurélio: 1) a definição por parte do chefe do Poder Executivo acerca dos serviços essenciais regulados por decreto afronta o princípio da separação de poderes caso não observe as autonomias locais; 2) "a MP não afasta os atos a serem praticados pelos estados, pelo Distrito Federal e pelos municípios, que têm competência concorrente para legislar sobre saúde pública (artigo 23, inciso II, da Constituição)". Contudo, há que se ressaltar que, na prática, as medidas provisórias não alteram o art. $3^{\circ}, \S 7^{\circ}$ da Lei, o qual se refere à cooperação federativa, e isso significa que o enfretamento da ADI não tinha como objetivo central a discussão dos níveis de cooperação no caso da pandemia, mas que o STF desejou em certa medida firmar posicionamento acerca do tema, indo ainda além do objeto do pedido. Enfatizase que, na discussão envolvendo a polícia sanitária, o Partido Democrático Trabalhista (PDT), responsável pela impetração da ação, fundamentou no sentido de que redistribuição de poderes de polícia sanitária introduzida pela MP 926/2020 na Lei Federal 13.979/2020 acabou interferindo no regime de cooperação entre os entes federativos, afinal, coube à União as prerrogativas de isolamento, quarentena, 
interdição de locomoção, de serviços públicos e atividades essenciais e de circulação. (BRASIL, ADI 6341 e 6343, STF, 2020).

Outra duas arguições de descumprimentos de preceito fundamental merecem destaque, a ADPF 672 proposta pela Ordem dos Advogados do Brasil, liminar do Ministro Alexandre de Moraes, além da ADPF 675 proposta pela Confederação Nacional do Turismo (CNTUR), que questionava decretos estaduais e municipais que estabelecem medidas de isolamento social para o enfrentamento ao novo coronavírus, de relatório do Ministro Celso de Mello.

No caso da ADPF 672, um dos debates centrais era a possível atuação pessoal do Presidente da República em nítido contraste com as diretrizes recomendadas pelas autoridades sanitárias de todo mundo, inclusive do Ministério da Saúde brasileiro, o que vem demostrando ainda mais a importância da atuação dos Municípios e Estados, conhecedores de suas realidades locais ao tomar medidas antes dos atos de omissão do governo federal. Novamente, a liminar concedida seguiu-se na alinha de reafirmar a possibilidade de adoção de medidas restritivas aos direitos fundamentais por Estados e Municípios, ante as constantes omissões ou mesmo contrariedades da Presidência da República e Ministério da Saúde em seguir as orientações da OMS. "para que seja determinado o respeito à determinação dos governadores e prefeitos quanto ao funcionamento das atividades econômicas e as regras de aglomeração". Frisa-se ainda que "o caráter discricionário das medidas realizadas pelo Presidente da República, bem como de suas eventuais omissões, é passível de controle jurisdicional" (...), lembrando que, tanto nos atos de omissão ou mesmo de contrariedade, o Presidente está vinculado ao império da lei, “(...) exigindo a obediência das autoridades ao Direito, e, em especial, ao respeito e efetividade aos direitos fundamentais." (BRASIL, ADPF 672, STF, 2020, p.08)

Já no caso da ADPF 675, mas uma vez a decisão liminar de Celso de Mello foi favorável ao entendimento de que Estados e Municípios teriam competência para impor medidas de isolamento social, e em face do pedido incerto e indeterminado ao não indicar quais as medidas e atos questionados o fazendo apenas de maneira genérica sem indicar órgãos ou autoridades, acabou por indeferir o pedido. (BRASIL, ADPF 675, STF, 2020)

Ainda pode-se referir as decisões e disputas judiciais envolvendo a aquisição de respiradores por Estados e Municípios, prevalecendo no STF a tese de que também compete a esses entes a adequada prestação do serviço público e a execução de 
ações de saúde, proibindo o controle exclusivo da União nesse sentido, casos do Rio de Janeiro (RS), em Cotia (SP), São Roque (SP), Recife e Maranhão.

Também a reclamação $\mathrm{Rcl}$ 39871, de relatório do Ministro Luis Roberto Barroso, deferiu parcialmente liminar na Reclamação (RCL) 39871, na qual a União questiona decisão do Tribunal Regional Federal da $1^{\text {a }}$ Região (TRF-1), que, a após declarada inconstitucionalidade de dispositivo da Medida Provisória 926/2020 que exige recomendação técnica da Agência Nacional de Vigilância Sanitária (Anvisa) para restrição de transporte de passageiros, reconheceu a validade do decreto estadual que proibiu o transporte fluvial de passeio no estado como medida de combate à pandemia da COVID-19. O caso revela "conflito pontual no exercício de competências legislativas concorrentes e político-administrativas comuns" e não há, a princípio, a alegada usurpação da competência do STF. (BRASIL, STF, Rcl 39871, 2020).

Essas decisões apenas exemplificativamente demostram que a discussão sobre o âmbito do exercício das competências, o tema envolvendo os níveis de cooperação federativa centralização e descentralização do tomada de decisão, assim como uma melhor definição do âmbito das competências para normas gerais e normas suplementares, é um antigo problema do federalismo brasileiro, o qual apenas se acentuou e evidenciou-se durante a COVID-19.

\section{CONSIDERAÇÕES FINAIS}

Parte significativa dos pesquisadores acredita que as federações produzem efeitos peculiares na dinâmica da formulação e implementação das políticas públicas e, nesse sentido, defendem a pertinência de tomá-las como variável independente. Porém, há também uma parte significativa que nega que o federalismo produza efeitos em uma única direção ou mesmo que possa ser tomado como um conjunto homogêneo, do que decorre em alguns casos a proposição de classificar as federações em diferentes tipos aos quais se poderia atribuir efeitos próprios sobre as políticas públicas. As respostas mais recentes a essa questão têm apontado na direção de que, considerando a variedade institucional e os diferentes graus de descentralização, o federalismo não seja de fato tomado isoladamente como uma variável independente, mas, sim, como um dos componentes institucionais que devem ser analisados de forma combinada a outros atributos contextuais para que possa 
ganhar relevância explicativa, especialmente para o desenvolvimento das políticas públicas.

A centralidade da tomada de decisão das políticas públicas não pode resultar no afastamento da sociedade da tomada de decisão, pois as demandas construídas a partir da proximidade da cidadão com o poder público de alguma forma precisam ser contempladas nas esferas institucionais, sob pena de alimentar um problema tão sério e relevante: as políticas públicas que não emergem da sociedade e para a sociedade agravam a nossa baixa e descompromissada cidadania. Ainda, no caso brasileiro, o modelo competitivo predatório, longe de promover o controle do poder entre as diversas esferas de governos e potencializar a resposta dos governos pela via das políticas públicas, tem acirrado as disputas internas de poder.

O caso das políticas públicas sociais e a COVID-19 somente revela o quanto os arranjos institucionais do federalismo brasileiro requerem a necessidade de decisão, e decisões coordenadas que não se afastem da possibilidade de participação e controle social nos três níveis federativos.

\section{REFERÊNCIAS}

ATALIBA, Geraldo. Regime Constitucional e Leis Nacionais e Federais. Revista de Direito Público, n. 53/54, p. 58-76, jan-jun, 1980.

ABRANCHES, Sérgio Henrique Hudson de. A Democracia brasileira vai bem, mas requer cuidados: proposições sobre democracia brasileira e o presidencialismo de coalizão. INAE - Instituto Nacional de Altos Estudos. Rio de Janeiro: 2001.

ABRANCHES, Sérgio Henrique Hudson de. Presidencialismo de coalizão: o dilema institucional brasileiro. DADOS - Revista de Ciências Sociais, Rio de Janeiro. v. 31. p. 5-34, 1988.

ABRUCIO. Fernando Luiz; COSTA, Valeriano Mendes Ferreira. Reforma do Estado e o Contexto Federativo Brasileiro. Centro de Estudos Konrad -Adenauer. Pesquisas, $\mathrm{n}^{\circ}$ 12. São Paulo, 1999.

ALBRIGHT, Madaleine. Fascismo: um alerta. Trad. Jaime Biaggio. São Paulo: Planeta, 2018.

ARRETCHE, M. Federalismo e políticas sociais no Brasil: problemas de coordenação e autonomia. São Paulo em Perspectiva, v. 2, n. 18, p. 17-26, 2004.

ARRETCHE, M. Federalismo e relações intergovernamentais no Brasil: a reforma de programas sociais. Dados, v. 45, n. 3, p. 431-58, 2002. 
ARRETCHE, M. Estado federativo e políticas sociais: determinantes da descentralização. Rio de Janeiro: Revan, 2000.

BERCOVICI, Gilberto. Planejamento e políticas públicas: por uma nova compreensão do papel do Estado. In: BUCCI, Maria Paula Dallari (org.). Políticas públicas: reflexões sobre o conceito jurídico. São Paulo: Saraiva, 2006. p. 143-162.

BITENCOURT, Caroline Müller, RECK, Janriê Rodrigues. Paradoxos do federalismo: uma observação pragmático-sistêmica. A\&C - Revista de Direito Administrativo \& Constitucional, Belo Horizonte, ano 12, n. 49, p. 151-176, jul./set. 2012.

BITENCOURT, Caroline Müller. Controle Jurisdicional de Políticas Públicas. Porto Alegre: Fabris, 2013.

BRASIL. [Constituição (1988)]. Constituição da República Federativa do Brasil. Brasília, DF, 5 out. 1988. Disponível em

http://www.planalto.gov.br/ccivil_03/constituicao/constituicao.htm. Acesso em: 20 out. 2019.

Decreto 10.212, de 30 de janeiro de 2020. Promulga o texto revisado do Regulamento Sanitário Internacional, acordado na 58a Assembleia Geral da Organização Mundial de Saúde, em 23 de maio de 2005. Disponível em: http://www.planalto.gov.br/ccivil_03/_ato2019-2022/2020/decreto/D10212.htm. Acesso em: 11 abr. 2020.

. Lei 13.979, de 06 de fevereiro de 2020. Dispõe sobre as medidas para enfrentamento da emergência de saúde pública de importância internacional decorrente do coronavírus responsável pelo surto de 2019.Disponível em: http://www.planalto.gov.br/ccivil_03/_ato2019-2022/2020/lei/L13979.htm. Acesso em: 11 abr. 2020.

. Lei 8080, de 19 de setembro de 1990. Dispõe sobre as condições para a promoção, proteção e recuperação da saúde, a organização e o funcionamento dos serviços correspondentes e dá outras providências. Disponível em: http://www.planalto.gov.br/ccivil_03/leis/l8080.htm. Acesso em: 11 abr. 2020.

. Medida Provisória 926, de 20 de março de 2020. Altera a Lei n 13.979, de 6 de fevereiro de 2020, para dispor sobre procedimentos para aquisição de bens, serviços e insumos destinados ao enfrentamento da emergência de saúde pública de importância internacional decorrente do coronavírus. Disponível: http://www.planalto.gov.br/ccivil_03/_ato2019-2022/2020/Mpv/mpv926.htm. Acesso em: 11 abr. 2020.

. Medida Provisória 926, de 22 de março de 2020. Dispõe sobre as medidas trabalhistas para enfrentamento do estado de calamidade pública reconhecido pelo Decreto Legislativo $n^{\circ}$ 6, de 20 de março de 2020, e da emergência de saúde pública de importância internacional decorrente do coronavírus (COVID-19), e dá outras providências. Disponível: http://www.planalto.gov.br/ccivil_03/_ato20192022/2020/Mpv/mpv927.htm. Acesso em: 11 abr. 2020. 
. Supremo Tribunal Federal. Ação Direta de Inconstitucionalidade $n^{\circ}$ 6342/DF Relator: Marco Aurélio. 15 abr. 2020. Disponível: https://portal.stf.jus.br/processos/detalhe.asp?incidente=5880968. Acesso em: 20 abr. 2020.

. Supremo Tribunal Federal. Ação Direta de Inconstitucionalidade $n^{\circ} 6341 / \mathrm{DF}$ Relator: Marco Aurélio. 15 abr. 2020. Disponível http://portal.stf.jus.br/processos/detalhe.asp?incidente=5880765. Acesso em: 20 abr. 2020.

Supremo Tribunal Federal. Arguição de descumprimento de preceito fundamental 672. Relator: Alexandre de Moares. 08 abr. 2015. Disponível: http://www.stf.jus.br/arquivo/cms/noticiaNoticiaStf/anexo/ADPF672liminar.pdf. em Acesso em: 20 abr. 2020.

Supremo Tribunal Federal. Arguição de descumprimento de preceito fundamental 675. Relator: Celso de Mello. 20 abr. 2015. Disponível: http://portal.stf.jus.br/processos/detalhe.asp?incidente=5892242. em Acesso em: 20 abr. 2020.

Supremo Tribunal Federal. Rcl 39871. Relator: Ministro Luis Roberto Barroso. 13 abr. 2015. Disponível:

http://portal.stf.jus.br/processos/detalhe.asp?incidente=5887672. em Acesso em: 20 abr. 2020.

BUCCI, Maria Paula Dallari. Fundamentos para uma teoria jurídica das políticas públicas. São Paulo: Saraiva, 2013.

BUCCI, Maria Paula Dallari; COUTINHO, Diogo. Arranjos jurídico-institucionais da política de inovação tecnológica: uma análise baseada na abordagem de direito e políticas públicas. In: COUTINHO, Diogo; FOSS, Maria Carolina; MOUALEM, Pedro Salomon (orgs.) Inovação no Brasil: avanços e desafios jurídicos e institucionais. São Paulo: Blucher, 2017, p. 313-340. Disponível em https://estudosinstitucionais.com/REl/article/view/443. Acesso em: 23 nov. 2019.

ECONOMIST INTELIGENCE UNIT. Democracy Index 2019. Disponível em: https://www.eiu.com/topic/democracy-index. Acesso em: 11 abr. 2020.

FALLETI, Tulia. Efeitos da descentralização nas relações intergovernamentais: o Brasil em perspectiva comparada. Sociologias, Porto Alegre, Ano 8, n. 16, p. 46-85, jul./dez. 2006

HABERMAS, Jürgen. A inclusão do outro. 3. ed.Trad. George Sperber, Paulo Astor Soethe e Milton Camargo Mota. São Paulo: Loyola, 2007.

LEVI, Lucio. Federalismo. In: BOBBIO, Norberto; MATTEUCI, Nicola; PASQUINO, Gianfranco (Org.). Dicionário de política. 11. ed. Brasília: Ed. UnB, 1998, v. 1, p. 475486.

LEVITSKY, Daniel; ZIBLATI, Steven. Como as democracias morrem. Rio de Janeiro: Zahar, 2018. 
MADISON, James; HAMILTON, Alexander; JAY, John. Os artigos federalistas. Trad. Maria Luiza X. de A. Borges. Rio de Janeiro: Nova Fronteira, 1993.

MENDES, Aquila.; MARQUES, Rosa Maria. O financiamento da Atenção Básica e da Estratégia Saúde da Família no Sistema Único de Saúde. Revista Saúde Debate. Rio de Janeiro, v. 38, n. 103, p. 900-916, out-dez. 2014 910, R. M. p.904. Disponível: http://www.scielo.br/pdf/sdeb/v38n103/0103-1104-sdeb-38-103-0900.pdfAcesso em: 23 fev. 2019.

PEREIRA, Rodolfo Vianna. Direito Constitucional democrático: controle de participação como elementos fundantes e garantidores de constitucionalidade. 2. ed. Rio de Janeiro: Lúmen Juris, 2010. p. 208.

RODRIGUES, Itiberê C. V. Fundamentos dogmático-jurídicos do sistema de repartição das competências legislativa e administrativa na Constituição de 1988. In: REIS, Jorge Renato dos; LEAL, Rogério Gesta (Org.). Direitos sociais e políticas públicas: desafios contemporâneos. Santa Cruz do Sul: Edunisc, 2008.

SCHIER. Paulo Ricardo. Linhas gerais do presidencialismo de coalizão no Brasil e seu vínculo com a questão da corrupção, 2014. Disponível em:

http://www.repozytorium.uni.wroc.pl/Content/71628/03_Paulo_Ricardo_Schier.pdf.

Acesso em: 30 mar. 2020.

SOARES; Márcia Miranda; MACHADO, José Ângelo. Federalismo e Políticas Públicas. Brasília: Enap, 2018.

Recebido em 18/07/2020

Aprovado em 20/11/2020

Received in 18/07/2020

Approved in 20/11/2020 